\title{
Exploration of the Local Clay in Removing the Blue Textile Dye from the Blue Stream Commonly Known as "Mabolou Running through Thetsane Industrial Area, Maseru
}

Mamatete Ntsapi, Bothaka Tubatsane, Limpho J Machachamise, Amohelang N Seotsanyana and Mosotho J George*

Department of Chemistry and Chemical Technology, National University of Lesotho, Lesotho

\begin{abstract}
As a search for affordable and efficient adsorbents for purification of textile wastewater continues, different natural materials are being investigated. Herein we report the investigation of clay obtained from Lesotho as a low cost and ecofriendly adsorbent for removal of blue textile dye from the stream running through the textile industry populated area in Ha Thetsane about $3 \mathrm{~km}$ South West of Maseru - the capital city of Lesotho. Batch adsorption studies were carried out for the effect of mass of adsorbent and particle size, $\mathrm{pH}$, temperature and contact time on the adsorption capacity of the blue dye on the clay. The results show that the smaller the particle size of the adsorbent the higher the efficiency, although the smaller particles could also clog the pores of the filter paper; the adsorption increases under the basic media $(\mathrm{pH} \geq 10)$ and at a low temperature $\left(10-15^{\circ} \mathrm{C}\right)$ achieving an extraction efficiency of $88 \%$ for a $4 \mathrm{~g}$ clay and a $15 \mathrm{~mL}$ solution after 15 minutes extraction relative to the original solution. Despite the identity of the dye not being known, the clay adsorbent was found to be quite effective for the removal of this dye. The focus of the future experiments will be to obtain the information from the factories through the relevant government departments about the identity of the dye so that definitive quantitative analysis could be carried out.
\end{abstract}

Keywords: Clay; Batch adsorption; Textile dye; Wastewater; Environmental pollution; Maseru

\section{Introduction}

As the world moves to improved livelihoods aspired by global conventions such as Sustainable Development Goals (SDGs) and Agenda 2063, most countries that find themselves in the Least Developed categories are still confronted with the challenges of environmental pollution - defined as any change, whether biological, chemical and or physical, in the quality of environment emanating from the human activity. Textile industry is one of the most common industries in the LDC countries due to the fact that it requires relatively lower capital investment for start-up as well as their ability to absorb a large number of unskilled manpower which provides a cushion for political instability resulting from lack of employment opportunities [1]. This situation is indeed prevailing in Lesotho where there is a huge shortage of employment opportunities due to the absence of industries [2]; as such the largest employer besides the public sector is the textile industry which employs between 40,000 and 50,000 people due to the convention between the USA and most African countries under the Africa Growth and Opportunities Act (AGOA) where products from these countries are waived from the tariffs by the former for the trade products from the latter [3]. This has increased the investment in the textile industry from the Far East, specifically China taking advantage of the AGOA opportunity. The environmental impact of this industry in Lesotho is far reaching with regards to the sludge and waste water from this industry as main source of employment [4].

Consequent of their inherent high pollution potential, textile industries contribute significantly to the international debates relating to international trans-boundary river systems $[5,6]$. Efforts are being made to reduce the extent of pollution such as landfilling the sludge that comes from the textile industries, which could also present a future challenge if the landfills are not properly constructed [7]. However, associated with the sludge is a release of copious amount of dyed wastewater that is used for dying the fabrics which is a nightmare to the sewerage authorities in places that host this industry [8]. Where law enforcement is not very effective, effluent from these factories may enter the streams partially or untreated thereby causing a huge environmental risk due to the concoction of chemicals including dyes [9]. There are worse instances when the said investors threaten governments of closing down when being pressured by the law enforcement agencies to be environmentally friendly, thus holding governments at ransom due to the potential consequences of such closures on the employment profile of such countries [10].

Clean water has become a subject of global debates with some predicting the Third World War to be over the clean water. The World Health Organization (WHO) estimates that nearly 1.2 billion people living on earth today have no access to clean drinking water with 3.2 million people, majority being children below the age of 5, dying of infectious water-borne diseases every year [11]. Delpy and Pyke suggested that even if the UN Millennium Development Goals would be reached by 2015, poor access to water resources alluded to by WHO as well as a reported 1 in 4 ratio of 4 people in living without live without sanitation facilities in the developing economies, warrants more chemical research in water sector [12]. Sources of water pollution are either point or non-point sources with point sources comprising sources such as pipes, ditches or sewer lines that discharge contaminants or pollutants into bodies of surface water [13]. These usually include factories, sewage treatment plants, underground mines, and city storm drains. Due to their specific locations it is relatively easy to identify, monitor and regulate them.

*Corresponding author: Mosotho J George, Department of Chemistry and Chemical Technology, National University of Lesotho, P.O. Roma 180, Lesotho, Tel: +266 5221 3502; Fax: +266 2234 0000; E-mail: jm.george@nul.ls

Received April 13, 2018; Accepted April 30, 2018; Published May 06, 2018

Citation: Ntsapi M, Tubatsane B, Machachamise LJ, Seotsanyana AN, George MJ (2018) Exploration of the Local Clay in Removing the Blue Textile Dye from the Blue Stream Commonly Known as 'Mabolou Running through Thetsane Industrial Area, Maseru. Int J Waste Resour 8: 340. doi: 10.4172/2252-5211.1000340

Copyright: ( 2018 Ntsapi M, et al. This is an open-access article distributed under the terms of the Creative Commons Attribution License, which permits unrestricted use, distribution, and reproduction in any medium, provided the original author and source are credited. 
Citation: Ntsapi M, Tubatsane B, Machachamise LJ, Seotsanyana AN, George MJ (2018) Exploration of the Local Clay in Removing the Blue Textile Dye from the Blue Stream Commonly Known as 'Mabolou Running through Thetsane Industrial Area, Maseru. Int J Waste Resour 8: 340. doi: $10.4172 / 2252-5211.1000340$

Page 2 of 5

With the advent of the climate change, a search for the renewable resources intensifies. This has led for the search for renewable materials that adds little to no extra carbon footprint to the atmosphere. This has thus led to the exploration of naturally occurring materials for the extraction of different chemical species in the environment. These includes as natural fibres - cellulosic [14] and keratin-based materials [15] such human hair [16,17], plant materials such as pine cones [18], rice husks [19], sawdust [20], just to mention a few; as well as natural silicates - clays [21]. These materials are important since they usually do not cost much for their production except a bit of purification before use. These materials have been reported in extraction of different analytes with differing success as per a recent review [22].

Clay is abundant in Lesotho where its use has in the main been in the production of clay bricks with only recent exploration into ceramics such as pottery. This abundance makes clay a potent alternative for removal of chemical pollutants. Consequently, in this report the potential of the clay that is used by the clay brick making company was assessed for removal of the blue dye, suspected to be methylene blue as a common textile dye, from water collected from a stream running downstream of the textile factories in Ha Thetsane Industrial area South West of Maseru - the capital City of Lesotho, a tiny country wholly landlocked inside South Africa. This stream is commonly known as 'Mabolou (the blue stream) owing to its permanent blue colour. There are at least three factories that make fabric from raw cotton hence they use conspicuous amounts of dyes and release their wastewater into this stream hence a source was easily identified. One study reported that due to inefficient treatment of the waste from the concerned factories, the effluent flowing downstream in to Caledon River $(<5 \mathrm{~km}$ downstream) was "one of the most turbid rivers in Southern Africa" [4]; this therefore warrants efforts to reduce the extent of pollution of this important river that also acts as an international border between Lesotho and South Africa.

\section{Materials and Methods}

\section{Chemicals and apparatus}

Only the analytical grade purity chemicals obtained from ACE (Johannesburg South Africa), were used in this study, namely, $\mathrm{NaCl}$, $\mathrm{HNO} 3, \mathrm{NaOH}$ and ethanol. Different concentrations of these chemicals were prepared by dissolving the appropriate amounts in distilled water prepared in-house using a laboratory water distiller.

The absorbance spectrum of the sample was measured using the Shimadzu 1201 UV-Vis Spectrophotometer (Kyoto Japan). Following this the wavelength that gave maximum absorbance was determined at which the further quantitative studies were measured. The $\mathrm{pH}$ was measured using a pH meter (Hanna Instruments, Romania).

\section{Collection and treatment of clay samples}

The finely ground clay sample (about $1 \mathrm{~kg}$ ) was obtained from the Technology Incubation Group at the University which was used for production of ceramics and clay bricks. This sample had been characterized before using X-ray diffraction technique in two different studies and produced the data shown in Table $1[23,24]$. This sample was washed with ethanol to remove all the organics that could be adsorbed on it and rinsed with copious amount of distilled deionized water before being dried in an oven at $40{ }^{\circ} \mathrm{C}$ thereafter stored in clean $\mathrm{Schott}^{\oplus}$ bottles away from organic compounds sources till further use.

\section{Collection and storage of the water samples}

The stream water was collected in $1000 \mathrm{~mL}$ Schott ${ }^{\circ}$ bottle from the stream running along the $\mathrm{Ha}$ Thetsane Industrial area downstream of the textile factories. However, due to their refusal for entry, the water samples were obtained several meters away from the said factories. These water samples were stored in a refrigerator at around $5^{\circ} \mathrm{C}$ when not in use. The samples were warmed to around room temperature $\left(25^{\circ} \mathrm{C}\right)$ before all the experiments except those requiring specific temperature.

\section{Extraction procedures and optimisation of different parameters}

The effect of different parameters on the adsorption of the dye was studied using batch experiments in a univariate manner. Portions of accurately weighed clay were added into a $100-\mathrm{mL}$ conical flask containing $15.0 \mathrm{~mL}$ water sample. The mixture was stirred for 10 minutes (except where the effect of extraction time was investigated, in which case the extraction time will be specified accordingly) and then filtered to attain a clear filtrate whose absorbance was measured. The different parameters that were studied included varying the adsorbent mass, particle size, $\mathrm{pH}$, temperature and contact time. The extractions were repeated three times $(n=3)$ using three different mixtures (intersample variation) as it was observed that the absorbance did not vary much when the absorbance of the same sample (intra-sample variation) was measured.

\section{Results and Discussion}

\section{Determination of the wavelength of maximum absorbance}

Since no standard was available, the study was based entirely on the sample from the mentioned stream. The sample gave a maximum absorbance at $668 \mathrm{~nm}$ and yielded a similar spectrum to the one for methylene blue found in literature as opposed to the other blue dyes [25]. Therefore, further experiments were carried out using this wavelength for quantitative analyses. Other studies reported relating to this stream hypothesised that this blue compound could be methylene blue [26]. However, the authors do not want to commit to this without any confirmatory tests for the compounds in the water sample, hence they decided to refer to the analyte as a blue dye in this report.

\section{Effect of varying the adsorbent mass}

About $15 \mathrm{~mL}$ sample portions were suspended in different masses of the clay samples ground and sieved at the particle size below 0.250 $\mathrm{mm}$ in a $100 \mathrm{~mL}$ conical flask. The mixture was continuously stirred for ten minutes using a stirring glass rod. Figure 1 shows the effect of varying the mass of clay used in the extraction of the blue dye following a 15 minute suspension. Despite the somewhat considerable error bars, it should be noted that these represent the $\% \mathrm{RSD} \leq 10 \%$.

As can be seen, the removal efficiencies of different masses of adsorbent changed significantly with increasing amount of adsorbent. The decrease in absorbance as the mass is increased seems almost linear $\left(\mathrm{R}^{2}=0.9727\right)$. This is due to the increase in availability of surface active sites resulting from the increased dose and conglomeration of the adsorbent. The adsorbent mass of $4 \mathrm{~g}$ was thus chosen as sufficient for adsorption of the dye achieving the lowest absorbance of 0.080 compared to the absorbance of about 0.095 obtained when using $1 \mathrm{~g}$ of adsorbent.

Effect of the adsorbent particle size on the extraction efficiency

Particle size is known for improved surface area hence the effect of 
Citation: Ntsapi M, Tubatsane B, Machachamise LJ, Seotsanyana AN, George MJ (2018) Exploration of the Local Clay in Removing the Blue Textile Dye from the Blue Stream Commonly Known as 'Mabolou Running through Thetsane Industrial Area, Maseru. Int J Waste Resour 8: 340. doi: $10.4172 / 2252-5211.1000340$

Page 3 of 5

\begin{tabular}{|c|c|c|c|c|}
\hline \multirow{2}{*}{ Material } & \multicolumn{4}{|c|}{$\%$ Abundance } \\
\hline & Reported by Nthunya L, et al. [23] & Reported by Masheane M, et al. [24] & Average & $\%$ RSD \\
\hline $\mathrm{SiO}_{2}$ & 71.13 & 71.8 & 71.46 & 0.66 \\
\hline $\mathrm{Al}_{2} \mathrm{O}_{3}$ & 14.47 & 14.5 & 14.48 & 0.17 \\
\hline $\mathrm{Fe}_{2} \mathrm{O}_{3}$ & 4.55 & 4.56 & 4.55 & 0.17 \\
\hline $\mathrm{K}_{2} \mathrm{O}$ & 2.45 & 2.45 & 2.45 & 0.12 \\
\hline $\mathrm{CaO}$ & 0.21 & 0.23 & 0.22 & 6.6 \\
\hline $\mathrm{MgO}$ & 0.6 & 0.7 & 0.65 & 11.05 \\
\hline $\mathrm{Na}_{2} \mathrm{O}$ & 0.1 & 0.1 & 0.1 & 0.17 \\
\hline $\mathrm{TiO}_{2}$ & 0.95 & 0.97 & 0.96 & 1.64 \\
\hline $\mathrm{P}_{2} \mathrm{O}_{5}$ & 0.01 & 0.01 & 0.01 & 0.17 \\
\hline
\end{tabular}

Table 1: Chemical composition of the clay used according to reported literature.

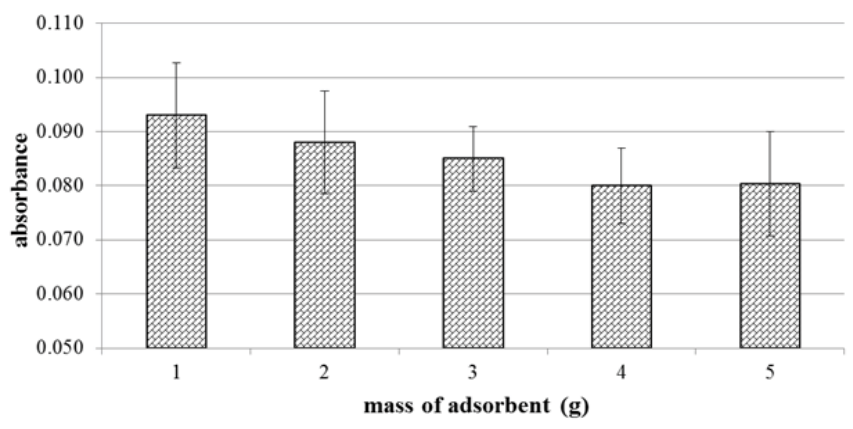

Figure 1: The effect of varying the adsorbent mass on absorbance of the water sample.

particle size is another important parameter to study. Different particle sizes were investigated using clay samples sieved through different particle sizes thus $0.841 \mathrm{~mm}, 0.250 \mathrm{~mm}$, and $0.177 \mathrm{~mm}$ respectively. The absorbances of the filtered samples were measured after the 15-minute suspension of the water samples in a clay adsorbent of about 4.0 g. Figure 2 shows the effect of particle size on the efficiency of the extraction.

The absorbance was found to decrease with decreasing particle size as depicted in Figure 2 this is possibly due to the larger surface area achieved by the smaller particles. The larger particles expose less surface area than smaller ones hence a loss in extraction efficiency. Despite the extraction efficiency being obtained with $0.177 \mathrm{~mm}$ particle size, the filter paper clogged and made filtration very difficult. Therefore the ideal particle size was chosen as $0.25 \mathrm{~mm}$ particle size. Grinding of adsorbent to various particle sizes does not only affect particle size but also reduced the regularity of crystalline structure of the adsorbent material, hence improving its analyte uptake.

\section{Effect of $\mathrm{pH}$ of the solution on the extraction efficiency}

The activity of the $\mathrm{H}+$ ions commonly known as $\mathrm{pH}$ is known to affect adsorption studies of different compounds on different materials differently. This depends mostly on the type of interactions between the analytes and the active sites of the adsorbent. The presence of a higher concentration of $\mathrm{H}+$ ions (lower $\mathrm{pH}$ values), the $\mathrm{H}+$ ions reduce the electron density of the active sites hence reduce the coordinative bonding of the adsorbent to the analytes, especially if the analytes are electrophilic. The effect of $\mathrm{pH}$ of the sample was studied by spiking the samples with different amounts of $\mathrm{HNO}_{3}$ and $\mathrm{NaOH}$ to a measured $\mathrm{pH}$ value. The $\mathrm{pH}$ of the original solution diluted appropriately was also measured. Figure 3 shows the effect of $\mathrm{pH}$ on the adsorption of

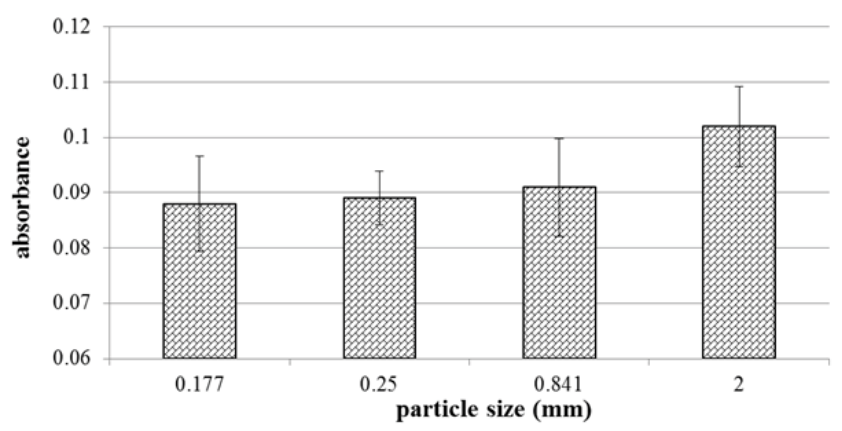

Figure 2: The effect of varying particle size of adsorbent on the uptake of the dye.

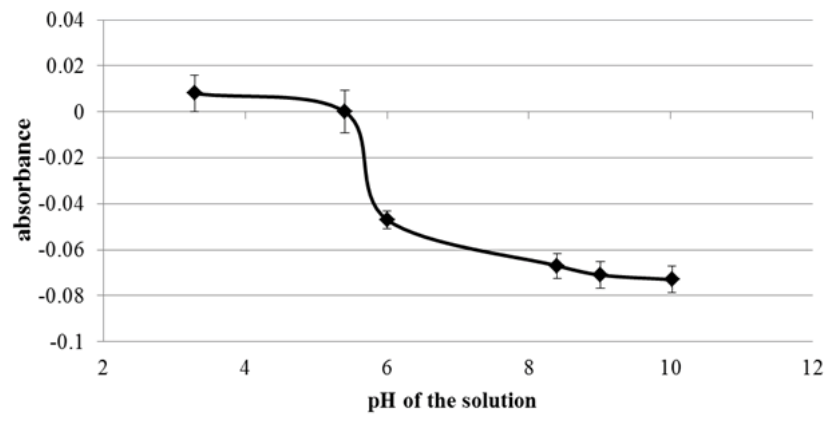

Figure 3: Effect of $\mathrm{pH}$ on the adsorption of the dye on clay (measured relative to the $\mathrm{pH}$ of the original solution -5.45 ).

the dye on the clay adsorbent using about $4 \mathrm{~g}$ of $0.25 \mathrm{~mm}$ particle and extraction time of 10 minutes.

As expected, absorbance decreases with decreasing $\mathrm{H}+$ ion activity, increasing $\mathrm{pH}$ values. This implies that the adsorbent becomes more efficient at alkaline conditions and less efficient at acidic conditions. This hints that the adsorption dynamics could involve some form of ion-exchange. At higher $\mathrm{pH}$, surface of adsorbent particles might become negatively charged, which enhance the positively charged dye through electrostatic forces of attraction and increases adsorption efficiency. Therefore the $\mathrm{pH}$ of 10 was chosen as an ideal $\mathrm{pH}$ for the extraction of the dye.

\section{The effect of temperature on the adsorption efficiency}

Temperature is very important in the dynamic processes since it affects the mass transfer between the two phases. However this could 
Citation: Ntsapi M, Tubatsane B, Machachamise LJ, Seotsanyana AN, George MJ (2018) Exploration of the Local Clay in Removing the Blue Textile Dye from the Blue Stream Commonly Known as 'Mabolou Running through Thetsane Industrial Area, Maseru. Int J Waste Resour 8: 340. doi: $10.4172 / 2252-5211.1000340$

Page 4 of 5

also demonstrate a negative effect in that the adsorbed analytes could also be desorbed back into the solution except where such adsorption is not dynamic (equilibrium-based). The effect of temperature was investigated by equilibrating the solutions in the water bath at respective temperatures prior to the introduction of the adsorbent material and as described in the prior sections. Figure 4 shows the effect of temperature $\left(10-30^{\circ} \mathrm{C}\right)$ on the efficiency of adsorption of the dye on the clay sample.

Clearly, absorbance increases with increasing temperature and this implies that the lower temperatures $-10^{\circ} \mathrm{C}$ and $15^{\circ} \mathrm{C}$ are favourable. The increase in absorbance as a result of temperature increase could be attributed to the lower binding of the dye onto the clay adsorbent, thus suggesting that the adsorption is dynamic (equilibrium-based) as the increase in temperature increases the mobility of the analytes to and fro the adsorbent material, with the reduction of the binding strength.

\section{The effect of contact time on the extraction efficiency}

To assess the effect of extraction time on the adsorption efficiency, all the optimised conditions were employed: $4.0 \mathrm{~g}$ mass of clay, 0.25 $\mathrm{mm}$ particle size, $\mathrm{pH}$ of 10 and the $15^{\circ} \mathrm{C}$ temperature. The samples were thereafter equilibrated at different times (5-30 minutes) as per Figure 5.

As can be seen, the extraction rate increases to about 15 minutes after which it levels off. This extraction profile follows the extraction timeprofile reported in many different analytes using different extraction techniques including liquid-based techniques [27]. Although the extraction efficiency at a glance seems to follow the first order kinetics, efforts to model this as a first order kinetics failed thus indicating a different kinetics order. Pseudo-second order kinetics for the uptake of $\mathrm{Cu}$ (II) ions using pine cones reported [18]. However the extraction

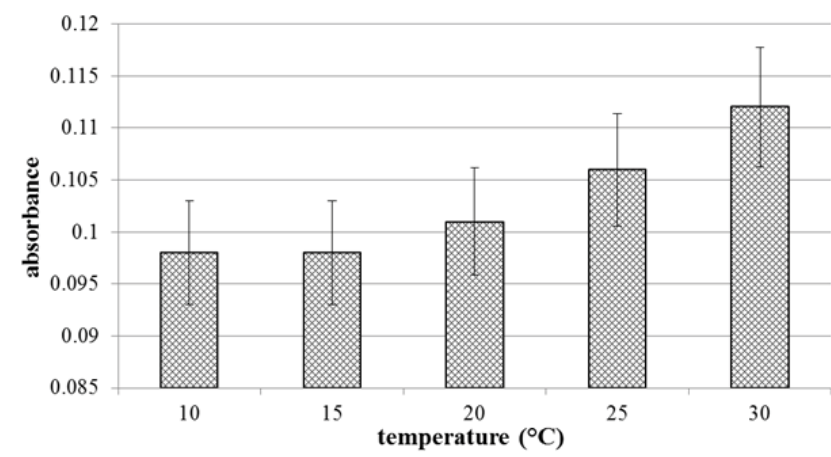

Figure 4: The effect of temperature of the solution on the extraction efficiency of the dye.

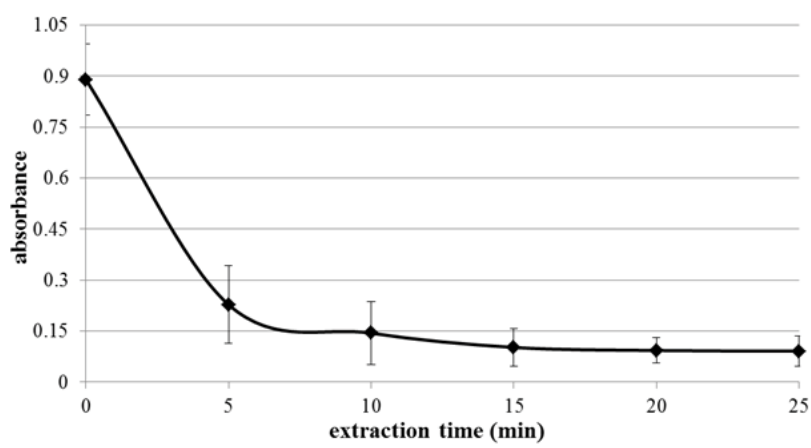

Figure 5: The extraction-time profile for the adsorption of the dye on clay using the optimised conditions. time was thus chosen to be 15 minutes where the efficiency of about $88 \%$ was realised using $4 \mathrm{~g} \times 0.25 \mathrm{~mm}$ clay at temperature of $15^{\circ} \mathrm{C}$ and $\mathrm{pH}$ of 10 extraction conditions.

The comparison of the extraction dynamics of methylene blue using this clay (this report) and the reported activated charcoal from rice by-products [28] shows consistent behaviour with regards to most parameters such as $\mathrm{pH}$ effect $(90 \%$ reported at $\mathrm{pH}>10)$, changing adsorbent mass (efficiency peaked at around $3 \mathrm{~g}$ of charcoal), as well as the smaller particle size demonstrating much higher efficiency. This report further put down a postulate regarding the probable adsorption mechanism attributing the reduced efficiency in the presence of $\mathrm{H}+$ ions (low $\mathrm{pH}$ values) to the protonation of the dye molecules hence reducing its binding (electron donation) to the clay particles. At a $\mathrm{pH}$ higher than the zero point $\mathrm{pH}$ of the surface, the adsorption increases due to the built-up of the negative charge on the surface. However, despite this making sense, without the positive identification of the dye and the absence of the standards, no assertions can be made towards this postulation as well as the determination of the other quantitative parameters such as loading capacity and the determination of the relevant isotherms. These will form a major part of the follow-up study in a near future with a known dye such as Methylene Blue which is suspected in this study.

\section{Conclusion}

This piece of work demonstrated the potential of clay for use as an efficient extraction material for purification of the blue dye from the waste water from the textile industries. Although the identity of the dye was not mad for quantitative analysis, the clay sample seems to extract about $88 \%$ (semi-quantitative) from the original solution. The optimum conditions for the extraction include $4 \mathrm{~g}$ of clay sample at 0.25 $\mathrm{mm}$, at the $\mathrm{pH}$ of 10 (basic $\mathrm{pH}$ conditions) and temperature of $15^{\circ} \mathrm{C}$ and the extraction time of 15 minutes. One of the important aspects of this work is the simplicity of the clay and its ready availability in Lesotho making it a highly potent adsorbent material. In conclusion, it can be stated that clay offers an alternative and affordable means for an effective removal of the textile dyes from wastewater which is an environmental nightmare in countries whose economic participation relies heavily on this type of industry such as Lesotho.

\section{References}

1. Keane J, Te Velde DW (2008) The role of textile and clothing industries in growth and development strategies. Overseas Development Institute, UK.

2. George MJ (2014) The status of food industry and associated socio-economic implications in Lesotho: Challenges and opportunities. J Sci Policy Govern 5 $1-11$.

3. CBL (2011) Africa Growth and Opportunities Act (AGOA): Economic Impact and Future Prospects. Central Bank of Lesotho Econonomic Reviews 131: 1-8.

4. Pullanikatil D (2007) Water pollution by industries in Lesotho. ATPS Working Paper Series 48: 1-23.

5. Brochmann M, Gleditsch NP (2012) Shared rivers and conflict:A reconsideration Political Geography 31: 519-527.

6. Morrissette JJ, Borer DA (2004) Where Oil and Water Do Mix: Environmental Scarcity and Future Conflict in the Middle East and North Africa. Parameters: U.S. Army War College Quarterly 34: 86-101.

7. Domina T, Koch K (1997) The Textile Waste Lifecycle. Clothing and Textile Research Journal 15: 96-102.

8. Khan S, Malik A (2013) Environmental and Health Effects of Textile Industry Wastewater. Environmental Deterioration and Human Health, pp: 55-71.

9. Chavan RB (2001) Indian Textile Industry - Environmental Issues. Indian J Fibre Textile Res 26: 11-21. 
Citation: Ntsapi M, Tubatsane B, Machachamise LJ, Seotsanyana AN, George MJ (2018) Exploration of the Local Clay in Removing the Blue Textile Dye from the Blue Stream Commonly Known as 'Mabolou Running through Thetsane Industrial Area, Maseru. Int J Waste Resour 8: 340. doi: $10.4172 / 2252-5211.1000340$

Page 5 of 5

10. George MJ (2016) Turning Resource Scarcity into an Abundance of Applied Research Opportunities in a Financially Strained University: The Case of Chemical Sciences at the National University of Lesotho. J Sci Policy Govern 8: 1-10.

11. World Health Organisation (2013) Diarrhoeal disease. WHO, Geneva.

12. Delpy D, Pike R (2010) The Economic Benefits of Chemistry Research to the UK.

13. Woodford C (2015) Water Pollution: An Introduction.

14. Belhalfaoui B, Aziz A, Elandaloussia EH, Oualia MS, De Ménorval LC (2009) Succinate-bonded Cellulose: A Regenerable and Powerful Sorbent for Cadmium-Removal from Spiked High-Hardness Groundwater. J Hazardous Materials 169: 831-837.

15. Aluigi A, Tonetti C, Vineis C, Tonin C, Mazzuchetti G (2011) Adsorption of Copper (II) lons by Keratin/PA6 Blend Nanofibres. European Polymer J 47: 1756-1764.

16. Ekop AS, Eddy NO (2010) Thermodynamic Study on the Adsorption of Pb2+ and $\mathrm{Zn} 2+$ from Aqueous Solution by Human Hair. E-Journal of Chemistry 7: 1296-1303.

17. George MJ, Ramollo N (2014) A Study of the Dynamics of Copper (II) lons Uptake from Aqueous Solutions by Human Hair using Conductivity and $\mathrm{pH}$ Measurements. Euro Chem Bulletin 3: 883-887.

18. Ofomaja AE, Naidoo EB, Modise SJ (2009) Removal of Copper (II) from Aqueous Solution by Pine and Base Modified Pine Cone Powder As Biosorbent. J Hazard Mater 168: 909-917.

19. Tarley CRT, Arruda MAZ (2003) Biosorption of Heavy Metals using Rice Milling By-Products Characterization and Application for Removal of Metals from

\section{Aqueous Effluents. Chemosphere 54: 987-995.}

20. Yasemin B, Zeki T (2007) Removal of Heavy Metals from Aqueous Solution by Sawdust Adsorption. J Environ Sci 19: 160-166.

21. Bouberka Z, Kacha S, Kameche M, Elmaleh S Derriche Z (2005) Sorption Study of an Acid Dye from an Aqueous Solutions using Modified Clays. J Hazard Mater 119: 117-124.

22. Geetha KS, Belagali SL (2013) Removal of Heavy Metals and Dyes Using Low Cost Adsorbents from Aqueous Medium - A Review. J Environ Sci Toxicol Food Technol 4: 56-68.

23. Nthunya L, George MJ, Méschac-Bill K, Masheane M, Mhlanga S (2016) Removal of Fe and Mn Heavy Metal Laden Water using Modified Clays.

24. Masheane M, Nthunya L, Mubiayi M, Thamae T, Mhlanga S (2018) PhysicoChemical Characteristics of Some Lesotho's Clays and Their Assessment for Suitability in Ceramics Production. Particulate Sci Technol 36: 117-122.

25. Ghaly AE, Ananthashankar R, Alhattab M, Ramakrishnan V (2014) Production Characterization and Treatment of Textile Effluents: A Critical Review. J Chem Eng Process Technol 5: 182-201.

26. Matsoso BJ (2013) Adsorption Study: Removal of Dyes from Textile Wastewater Using Clay. National University of Lesotho, Lesotho.

27. Williams DBG, George MJ, Meyer R, Marjanovic L (2011) Bubbles in Solvent Microextraction: The Influence of Intentionally Introduced Bubbles on Extraction Efficiency. Analytical Chem 83: 6713-6716.

28. Rahman MA, Amin SMR, Alam AMS (2012) Removal of Methylene Blue from Waste Water using Activated Carbon Prepared from Rice Husk. Dhaka Uni J Sci 60: 185-189. 